\title{
Fexapotide triflutate: results of long-term safety and efficacy trials of a novel injectable therapy for symptomatic prostate enlargement
}

\author{
Neal Shore ${ }^{1}$ (D) Ronald Tutrone ${ }^{2} \cdot$ Mitchell Efros $^{3} \cdot$ Mohamed Bidair $^{4} \cdot$ Barton Wachs $^{5} \cdot$ Susan Kalota ${ }^{6}$. \\ Sheldon Freedman ${ }^{7}$. James Bailen ${ }^{8} \cdot$ Richard Levin $^{9} \cdot$ Stephen Richardson $^{10}$. Jed Kaminetsky ${ }^{11}$. Jeffrey Snyder ${ }^{12}$. \\ Barry Shepard $^{13} \cdot$ Kenneth Goldberg ${ }^{14} \cdot$ Alan Hay $^{15} \cdot$ Steven Gange ${ }^{16} \cdot$ Ivan Grunberger $^{17}$
}

Received: 12 September 2017 / Accepted: 19 January 2018 / Published online: 29 January 2018

(c) The Author(s) 2018. This article is an open access publication

\begin{abstract}
Purpose These studies were undertaken to determine if fexapotide triflutate $2.5 \mathrm{mg}$ transrectal injectable (FT) has significant long-term (LT) safety and efficacy for the treatment of benign prostatic hyperplasia (BPH).

Methods Two placebo controlled double-blind randomized parallel group trials with $995 \mathrm{BPH}$ patients at 72 sites treated 3:2 FT:placebo, with open-label FT crossover (CO) re-injection in 2 trials $n=344$ and long-term follow-up (LF) 2-6.75 years (mean 3.58 years, median 3.67 years; FT re-injection CO mean 4.27 years, median 4.42 years) were evaluated. 12 months post-treatment patients elected no further treatment, approved oral medications, FT, or interventional treatment. Primary endpoint variable was change in Symptom Score (IPSS) at 12 months and at LF. CO primary co-endpoints were 3-year incidence of (1) surgery for BPH in FT treated CO patients versus patients crossed over to oral BPH medications and (2) surgery or acute urinary retention in FT-treated $\mathrm{CO}$ placebo patients versus placebo patients crossed over to oral BPH medications. $28 \mathrm{CO}$ secondary endpoints assessed surgical and symptomatic outcomes in FT reinjected patients versus conventional BPH medication $\mathrm{CO}$ and control subgroups at 2 and 3 years.

Results FT injection had no significant safety differences from placebo. LF IPSS change from baseline was higher in FT treated patients compared to placebo (median FT group improvement -5.2 versus placebo $-3.0, p<0.0001$ ). LF incidence of AUR $(1.08 \% p=0.0058)$ and prostate cancer $(\mathrm{PCa})(1.1 \% p=0.0116)$ were both reduced in FT treated patients. LF incidence of intervention for BPH was reduced in the FT group versus oral BPH medications $(8.08 \%$ versus $27.85 \%$ at 3 years, $p<0.0001)$. LF incidence of intervention or AUR in placebo CO group with FT versus placebo CO group with oral medications was reduced $(6.07 \%$ versus $33.3 \%$ at 3 years, $p<0.0001) .28 / 28$ secondary efficacy endpoints were reached in LF CO re-injection studies.

Conclusions FT $2.5 \mathrm{mg}$ is a safe and effective transrectal injectable for LT treatment of BPH. FT treated patients also had reduced need for BPH intervention, and reduced incidence of PCa and AUR.
\end{abstract}

Keywords BPH $\cdot$ Urology $\cdot$ LUTS $\cdot$ Fexapotide triflutate $\cdot$ NX-1207

\section{Introduction}

Benign prostatic hyperplasia begins in middle age and affects the majority of men by age 70-80 [1-7]. BPH leads to chronic lower urinary tract symptoms (LUTS) that may

Electronic supplementary material The online version of this article (https://doi.org/10.1007/s00345-018-2185-y) contains supplementary material, which is available to authorized users.

Neal Shore

NShore@gsuro.com

Extended author information available on the last page of the article necessitate interventional therapy if the symptoms are deemed excessively bothersome or otherwise are adversely affecting patients' health status. Prostate enlargement may cause urethral compression, diminished urinary flow, bladder hypertrophy, urinary urgency, frequency, nocturia, straining, urinary tract infections, and urinary retention which can lead to obstructive nephropathy. Management includes diagnostic evaluation to exclude prostate cancer or benign conditions that are not attributable to prostate hyperplasia, treatment options with medications (alpha blockers; 5-alpha reductase inhibitors), and interventional therapies when necessary, such as transurethral minimally invasive 
surgical treatments (MIST) or invasive surgery (transurethral resection (TURP) or laser ablation) [1-7]. Oral medications and surgical treatments may be associated with unacceptable adverse events. Medications are oftentimes stopped due to poor risk:benefit ratio as well as tachyphylaxis, adherence, cost, and other drug interactions [8-16]. TURP, historically acknowledged as the 'gold standard', is effective but associated with anesthetic risk, post-operative morbidities of voiding discomfort, bleeding, incontinence, and potential sexual dysfunction.

FT is a new molecular entity which stimulates caspase pathways (activation of caspases 7,8, and 10, caspase recruitment domains 6,11 , and 14 , and DIABLO), tumor necrosis factor pathways (activation of TNF1, TNFSF6, TNFSF8, TNFSF9, CD70 ligands, and TNFRSF19L, TNFRSF25, TRAF2, TRAF3, TRAF4, TRAF6 receptors), and BCL pathways (activation of BIK, HRK, BCL2L10 and BCL3) in prostate glandular epithelial cells. FT selectively causes loss of cell membrane integrity, mitochondrial metabolic arrest, depletion of RNA, DNA lysis and aggregation, and cell fragmentation and cell loss (Online Figures 2, 3) with subsequent decompression of the urethral lumen.jOn the basis of evidence from detailed toxicology studies in dogs given injections of FT directly into adjacent structures (bladder, urethra, rectum, periprostatic tissue) the adjacent tissues are unaffected. The underlying safety of FT is based on: 1. selective sparing of critical structures (nerves, periprostatic tissue, bladder, urethra, and rectum) (Online Figure 2); 2. pharmacokinetic (PK) properties which limit extraprostatic exposure; 3 . route of administration without a catheterization or significant anesthetic requirement; 4 . avoidance of detectable immune response; and 5. an absence of an effect on testosterone or subsequent ejaculatory parameters. FT is administered as an outpatient ultrasound guided transrectal (TR) injection into the transition zone. The procedure time requirement is approximately $3-5 \mathrm{~min}$ and does not require a urethral catheter, intravenous or general anesthetic, and apart from a standard TRUS requires no specialized equipment or instrumentation $[17,18]$.

This report presents the safety and efficacy data from 2 long-term follow-up (LF) prospective double-blind randomized placebo controlled studies and 2 crossover (CO) studies of FT for BPH involving 995 patients at 72 U.S. sites conducted from 2009 to 2017.

\section{Patients and methods}

NX02-0017 and NX02-0018 (0017/0018) were randomized, double-blind, parallel group studies designed to demonstrate safety and efficacy of transrectal ultrasound (TRUS) guided intraprostatic FT $2.5 \mathrm{mg}$ in $10 \mathrm{~mL}$ phosphate buffered saline (PBS) sterile solution, compared to placebo $10 \mathrm{~mL}$ (vehicle alone), directed to the transition zone ( $5 \mathrm{~mL}$ to each side) with the needle tip and injection as visualized by TRUS [17, 18]. Studies were conducted at 72 U.S. sites (85 U.S. sites approved and initiated; 80 with patient screening and assessments; 72 with patient enrollments) from 2009 to 2017, approved by institutional review boards and FDA (clinicaltrials.gov: NCT00918983, NCT00945490, NCT01438775, NCT01846793). Informed consent was obtained from all individual participants included in the study. Patients were enrolled based on BPH Symptom Score (IPSS), TRUS prostate volume (PV), urinary peak flow rate (Qmax) (Online Table 1). Patients were centrally randomized in a 3:2 ratio FT:placebo by a computer-generated randomization schedule executed by non-study personnel at an independent randomization service provider with no contact except by interactive voice response system. Patients, investigators, all site and non-site study personnel, monitors, and outcome assessors were blinded as to randomization. The following were captured at baseline and 10 days, 1, 3, 6, 9, 12 months: IPSS, Qmax (3, 6, 12 months), PV (12 months), BPH Impact Index (BII), Sexual Function Questionnaire (SFQ), and safety parameters. IPSS, BPH treatments and urological events were prospectively captured at LF. Crossover studies: 351 patients after completion of 0017/0018 (maintaining initial treatment double blind) were randomized $(n=344$ treated) at intervals of 0.5-39.1 months after the first year (mean 20.4 (SD 7.15) months post-randomization) into 2 open-label FT re-injection 6 month studies NX02-0020 and NX02-0022 (0020/0022) with additional LF. 0020/0022 were required for re-injection safety/efficacy data and for patient access to FT after 1 year. Blinded patients could elect no further treatment; oral conventional BPH medications; surgical treatment; or FT treatment. LF pre-specified comparator outcomes included objective measures of incidence of surgery and incidence of AUR, as well as self-reported IPSS and nocturia scores. Safety outcomes (including sepsis, new incidence of prostate cancer, etc.) were pre-planned.

\section{Statistical methods}

The ITT (Intent-to-treat) population included all injected patients with $\geq 1$ post-treatment IPSS. Primary Outcome (PO) in 0017/0018 was change in IPSS from baseline to 365 days and at LF. The PO variable did not change throughout the 0017/0018 trials. LF PO data capture did not change and was pre-specified in the 2009 protocols which included the LF questionnaires. These are the first ever adequately powered Phase $3 \mathrm{BPH}$ injectable trials to be fully accrued and completed in the U.S. Therefore, the LF date was not determined until after the 1 year capture was completed (5.0 years after first patient in). The crossover 0020/0022 PO variable did not change during the trial visits (6 months). The 0020/0022 LF extension data 
capture was pre-specified in the initial protocols (2012) which included LF questionnaires and was unchanged. 0020/0022 LF efficacy PO variables and 28 additional secondary outcome variables were pre-specified initially in the LF Statistical Plan and were unchanged. 0017/0018 were powered with a sample size of 500 subjects ( $300 \mathrm{FT}$ : 200 Placebo) for PO assuming a 2-sided mean value t test with 0.05 error and $80 \%$ power. Secondary endpoints, prespecified PO subgroups, and additional efficacy endpoints are summarized online. For LF PO analysis all treatment failures were included (worst case scenario analysis). Patients with post-randomization BPH surgery/MIST at anytime were treated as failures ( 0 change from baseline regardless of any prior reported improvement, or were treated $>0$ if last reading prior to withdrawal reported worsening). Patients who withdrew consent due to lack of efficacy, or who refused to participate were treated as treatment failures ( 0 change from baseline) regardless of prior reported improvement. Patients who subsequently took medications were treated as their last $\geq 0$ worsening value unless they had reported improvement $(<0)$ prior to taking medications in which instances they were excluded. Patients lost to follow-up (LTFU) after multiple documented attempts to reach them, were excluded. Missing values were analyzed according to multiple imputations. LF outcomes in CO 0020/0022: Incidence of BPH surgery and AUR within 24 and 36 months post-randomization were compared according to the groups in Table 3 and Online Figure 1. Mean IPSS and nocturia response were compared using $t$ tests or non-parametric tests. The Co-POs were 1. Incidence of BPH surgery in 0017/0018 patients with CO FT, compared to 0017/0018 patients who had subsequent conventional BPH medications; 2 . Incidence of BPH surgery or AUR in placebo 0017/0018 patients with CO FT, compared to placebo 0017/0018 with subsequent medications. Other group comparisons are in 28 additional Secondary Endpoints (Table 3). Step-down was by closed test procedure.

\section{Results}

0017/0018 enrolled 498 (1212 screened) and 497 (1224 screened) patients, respectively. Baseline characteristics, demographics, and patient disposition are summarized in Online Tables 2, 3, 4 and CONSORT diagram (Fig. 1). ITT lost to follow-up percentages were $1.4-1.6 \%$ at 12 months and $7.1-7.3 \%$ at LF (mean 43 months). At LF $2.9 \%$ of patients had unrelated serious adverse events (SAEs) or death, or otherwise inability to provide a valid questionnaire response (e.g., dementia or other exclusion criteria).
LF was 2-6.75 years (mean 3.58 years, median 3.67 years; FT re-injection CO mean 4.27 years, median 4.42 years).

\section{Safety and side effects}

AE data and laboratory results were similar in FT and placebo groups. Reported related AEs in both groups were from prophylactic antibiotics and needle insertion; these AEs were mainly mild, transient and not requiring treatment. Unrelated deaths in the FT group were $0.5 \%$ in the first 12 months ( 2 unrelated myocardial infarctions and 1 pre-existent pulmonary fibrosis), versus $0.25 \%$ in placebo (1 unrelated suicide at 9 months). In the reinjection $\mathrm{CO}$ studies there were no deaths during the first year post-treatment. Incidence of culture confirmed urinary tract infection (UTI) $<30$ days post-treatment was not increased $(0.6 \%$ in FT and $0.5 \%$ in placebo) and there were no cases of urosepsis in FT-treated patients. After 12 months, all statistical analyses of hematological and clinical chemistry parameters showed no changes, and mean serum PSA values were not significantly altered. Semen analyses of a subgroup of $n=41$ FT samples and $n=32$ placebo consecutively available samples were overall unchanged from baseline and no FT changes versus placebo were found. Anti-FT antibodies were not detected in $n=1072$ samples $(n=574$ FT $n=498$ controls). PK analyses of $n=106$ consecutive plasma samples drawn at 1, 5, 10 and 20 min post FT injections showed no extraprostatic systemic signal. After 4 years PCa newly diagnosed after the first 12 months in FT treated (1.1\%) was reduced compared to placebo $(5.3 \%)(p=0.0116)$ (Table 1$)$. Incidence of spontaneous AUR within 3 years in the FT group was reduced (1.08\%) compared to placebo population $(5.63 \%)(p=0.0058)$ (Table 1). There were no transient or persistent FT-related sexual side effects.

\section{Efficacy: primary endpoints}

0017/0018 LF PO was met in both 0017/0018 and in the pooled studies (Table 2) (0017: FT mean -5.1 , median -4.0 vs placebo $-3.8,-3.5, p=0.0378$ (Wilcoxon); 0018: FT mean -6.4 , median -6.3 vs placebo $-4.2,-3$, $p<0.0001$ (Wilcoxon); pooled 0017/0018 FT mean -5.7 , median -5.2 vs placebo $-4.0,-3.0, p<0.0001$ (Wilcoxon). At 1 year there was significant $\mathrm{FT}$ group change from baseline but not versus placebo. $P O$ subgroup $L F$ analyses were statistically significant in all but one (BPH history $\geq 10$ years) of adequately powered pre-planned subgroups. Except where noted, all of the following FTtreated subgroups showed statistically significant LF reductions in IPSS: Age; Ethnicity; Prior use of BPH treatment (Online Table 5); Prior medical therapy; BPH history; Baseline IPSS; Baseline PV; Baseline Qmax. Similar to the $\mathrm{PO}$ at 1 year, secondary endpoints showed significant 


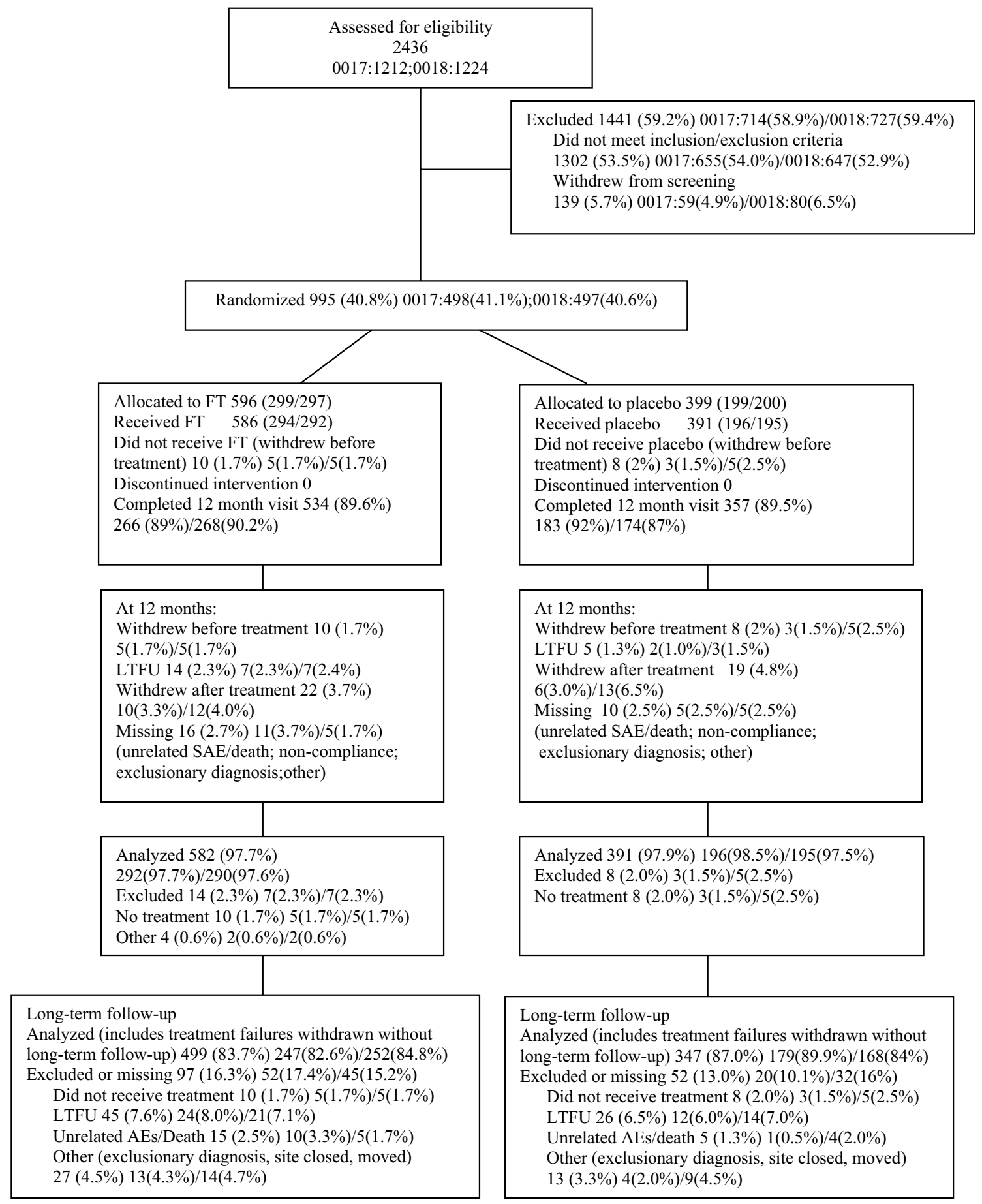

Fig. 1 CONSORT diagram of patient enrollment, allocations, treatment and follow-up

differences from baseline in the FT groups but did not meet the 12 month secondary efficacy endpoints versus placebo. At 10 days post-treatment there was statistically significant difference in IPSS change from baseline versus placebo in $0017(p=0.0011)$ and in the pooled studies $(p=0.0032)$. Additional Pre-Planned Efficacy Endpoints (online pages 2, 3, 9): LF responder analysis was statistically significant
(IPSS change $<0: 0017, p=0.0099 ; 0018, p=0.0023$ pooled studies $p<0.0001$. Responder analysis with cutoffs $<-1,<-2$, and $<-3$ IPSS improvement were all $p=<0.0001$ in the pooled studies (Online Table 6). Pre-specified CO efficacy endpoints in 0017/0018 patients who received FT re-injection in CO studies 0020/0022 are listed in Table 3. The LF co-POs were both significant: 1 . 
Table 1 Incidence of prostate cancer and spontaneous AUR. NX020017, NX02-0018, NX02-0020, and NX02-0022

\begin{tabular}{|c|c|c|c|c|c|}
\hline & \multicolumn{2}{|c|}{ FT $2.5 \mathrm{mg}$} & \multicolumn{2}{|c|}{ Placebo } & \multirow[t]{2}{*}{$p$ value } \\
\hline & $N$ & $\%$ & $N$ & $\%$ & \\
\hline $\begin{array}{l}\text { Patients } \\
\text { with } \\
\text { prostate } \\
\text { cancer }\end{array}$ & $349^{\mathrm{a}}$ & $1.1(4 / 349)$ & $95^{\mathrm{b}}$ & $5.3 \%(5 / 95)$ & $0.0116^{\mathrm{c}}$ \\
\hline $\begin{array}{r}\text { Incidence } \\
\text { of AUR }\end{array}$ & $277^{\mathrm{d}}$ & $1.08 \%(3 / 277)$ & $142^{\mathrm{e}}$ & $5.63 \%(8 / 142)$ & $0.0058^{\mathrm{c}}$ \\
\hline
\end{tabular}

${ }^{\text {a } P a t i e n t s ~ w h o ~ r e c e i v e d ~ F T ~ a t ~ l e a s t ~ o n c e ~ i n ~} 0017,0018,0020$, or 0022 with $\geq 4$ years $\mathrm{LF}$

${ }^{b}$ Patients who received Placebo in $0017 / 0018$ and not CO to FT, with $\geq 4$ years $\mathrm{LF}$

${ }^{\mathrm{c}} \mathrm{Chi}$-square test

${ }^{\mathrm{d}}$ All patients in $\mathrm{CO}$ studies with $\geq 3$ years follow-up

${ }^{\text {e}}$ Placebo patients in studies $0017 / 0018$ not CO to FT, with $\geq 3$ years follow-up

3-year incidence of BPH surgery in all CO FT (8.08\%) versus all BPH medications $(27.85 \%)(p<0.0001)$; and 2. 3-year incidence of BPH surgery or AUR in placebo CO FT $(6.07 \%)$ versus placebo with medications (33.3\%) $(p<0.0001)$. Supplementary analysis of PO Subgroup data: (Online Table 7).

\section{Discussion}

The main findings of the 4 studies reported are summarized as follows: 1. LF symptomatic improvement from a single FT treatment under double blind conditions was statistically significant (mean IPSS -5.7 points, placebo -4.0 , median -5.2 vs $-3.0, p<0.0001$ ); 2 . LF (3 year) FT reduction in incidence of BPH surgery in all CO patients (CO FT 8.08\%) versus all non-CO patients with conventional oral medications was obtained $(27.85 \%, \mathrm{p}<0.0001)$ (LT CO Primary Endpoint \#1) (Table 3); 3. LF CO (3 year) reduction in incidence of spontaneous AUR (CO FT 1.08\%, non-CO placebo $5.63 \%, p=0.0058$ ) was observed; 4 . LF (4 year) reduction in incidence of PCa newly diagnosed after 12 months or later (FT $1.1 \%$, placebo $5.3 \%, p=0.0116$ ) was observed; 5 . LF IPSS improvement after single injection FT with later conventional oral medications (mean -8.28 points) versus placebo with oral medications $(-4.74, p=0.0094)$ was found; 6. LF IPSS improvement in first-line (treatmentnaïve) patients (FT mean -6.6 points, placebo -4.0 , median -6.2 versus $-3.0, p<0.0001$ ) and in prior $\mathrm{BPH}$ treatment patients was found; 7 . Sexual function improvements in first-line FT treated patients $(+0.64$ points) versus worsening $(-0.88$ points $)$ in placebo patients $(p=0.0049)$; 8. LF (3 year) reduction in the incidence of BPH surgery or AUR (placebo CO FT $6.09 \%$ versus placebo CO conventional medications $33.3 \%, p<0.0001$ ) (LF CO Primary

Table 2 Change in BPH Symptom Score (IPSS) from baseline to long-term follow-up

\begin{tabular}{|c|c|c|c|c|c|c|c|c|c|c|}
\hline \multirow[t]{3}{*}{ Visit } & \multirow[t]{3}{*}{ Statistic } & \multicolumn{3}{|l|}{ NX02-0017 } & \multicolumn{3}{|l|}{ NX02-0018 } & \multicolumn{3}{|c|}{$\begin{array}{l}\text { Pooled studies NX02-0017 and } \\
\text { NX02-0018 }\end{array}$} \\
\hline & & FT $2.5 \mathrm{mg}$ & Placebo & $p$ value $^{\mathrm{b}}$ & FT $2.5 \mathrm{mg}$ & Placebo & $p$ value $^{\mathrm{b}}$ & FT $2.5 \mathrm{mg}$ & Placebo & $p$ value $^{\mathrm{b}}$ \\
\hline & & $N=292$ & $N=196$ & & $N=290$ & $N=195$ & & $N=582$ & $N=391$ & \\
\hline \multirow[t]{4}{*}{ Baseline $^{\mathrm{a}}$} & $n$ & 292 & 196 & - & 290 & 195 & - & 582 & 391 & - \\
\hline & Mean (SD) & 23.3(4.93) & $23.1(5.04)$ & - & $23.7(4.98)$ & $23.2(5.13)$ & - & $23.5(4.96)$ & $23.2(5.08)$ & - \\
\hline & Median & 23.0 & 23.0 & - & 24.0 & 23.0 & - & 23.5 & 23.0 & - \\
\hline & Min-max & $12.0-35.0$ & $15.0-35.0$ & - & 15.0 to 35.0 & 15.0 to 35.0 & - & 12.0 to 35.0 & 15.0 to 35.0 & - \\
\hline \multirow{4}{*}{$\begin{array}{l}\text { Change } \\
\text { from } \\
\text { Baseline } \\
\text { (Visit 10) }\end{array}$} & $n$ & 292 & 196 & - & 290 & 195 & - & 582 & 391 & - \\
\hline & Mean (SD) & $-5.3(6.81)$ & $-6.1(7.35)$ & - & $-6.6(6.41)$ & $-6.3(6.83)$ & - & $-6.0(6.64)$ & $-6.2(7.09)$ & - \\
\hline & Median & -5.0 & -5.2 & 0.1871 & -5.0 & -6.0 & 0.5402 & -5.0 & -5.8 & 0.5760 \\
\hline & Min-max & $-27-9.0$ & $-29-14.0$ & - & -26 to 10.0 & -28 to 9.0 & - & -27 to 10.0 & -29 to 14.0 & - \\
\hline \multirow{4}{*}{$\begin{array}{l}\text { Change } \\
\text { from } \\
\text { Baseline } \\
\text { (Follow- } \\
\text { up) }\end{array}$} & $n$ & 292 & 196 & - & 290 & 195 & - & 582 & 391 & - \\
\hline & Mean (SD) & $-5.1(6.23)$ & $-3.8(5.98)$ & - & $-6.4(5.78)$ & $-4.2(6.09)$ & - & $-5.7(6.05)$ & $-4.0(6.03)$ & - \\
\hline & Median & -4.0 & -3.5 & 0.0378 & -6.3 & -3.0 & $<0.0001$ & -5.2 & -3.0 & $<0.0001$ \\
\hline & Min-max & $-33-6.0$ & -25 to 16.0 & - & -25 to 8.0 & -27 to 13.0 & - & -33 to 8.0 & -27 to 16.0 & - \\
\hline
\end{tabular}

$N$ number of patients within the population and treatment group based on the available observations

$n$ number of available observations

${ }^{\mathrm{a}}$ Baseline $=$ Last available value before treatment

${ }^{\mathrm{b}}$ Normality assumption not met and $p$ value was based on non-parametric Wilcoxon rank sum test 
Table 3 Crossover (CO) efficacy endpoints, studies NX02-0020 and NX02-0022

\begin{tabular}{|c|c|c|c|c|c|c|c|}
\hline \multirow{2}{*}{\multicolumn{2}{|c|}{$\frac{\text { Endpoint }}{\text { Surgery }<3 \text { year }}$}} & \multirow{2}{*}{ 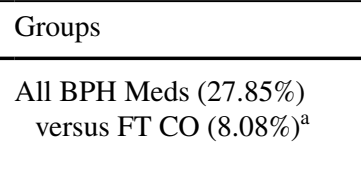 } & \multirow{2}{*}{$\frac{p \text { value }}{<0.0001}$} & \multicolumn{2}{|l|}{ Endpoint } & Groups & \multirow{2}{*}{$\frac{p \text { value }}{<0.0001}$} \\
\hline & & & & Surgery $<3$ year & & $\begin{array}{l}\text { Placebo with BPH Meds } \\
(30.30 \%) \text { versus Placebo } \\
\text { FT CO }(5.22 \%)\end{array}$ & \\
\hline Surgery or AUR $<3$ year & & $\begin{array}{l}\text { Placebo with BPH Meds } \\
(33.33 \%) \text { versus Placebo } \\
\text { FT CO }(6.09 \%)^{\mathrm{b}}\end{array}$ & $<0.0001$ & Surgery $<3$ year & & $\begin{array}{c}\text { Placebo not in CO }(16.44 \%) \\
\text { versus FT CO }(8.08 \%)\end{array}$ & 0.0100 \\
\hline Surgery $<2$ year & & $\begin{array}{l}\text { Placebo with BPH Meds } \\
(17.14 \%) \text { versus Placebo } \\
\text { FT CO }(0.78 \%)\end{array}$ & $<0.0001$ & Surgery $<2$ year & & $\begin{array}{l}\text { All BPH Meds }(14.10 \%) \\
\text { versus FT CO }(1.76 \%)\end{array}$ & $<0.001$ \\
\hline Surgery $<2$ year & & $\begin{array}{c}\text { Placebo not in CO }(9.04 \%) \\
\text { versus FT CO }(1.76 \%)\end{array}$ & 0.0002 & Surgery or AUR $<3$ year & & $\begin{array}{c}\text { All BPH Meds }(28.75 \%) \\
\text { versus FT CO }(8.85 \%)\end{array}$ & $<0.0001$ \\
\hline Surgery or AUR $<3$ year & & $\begin{array}{c}\text { Placebo not in CO }(17.81 \%) \\
\text { versus FT CO }(8.85 \%)\end{array}$ & 0.0078 & Surgery or AUR $<2$ year & & $\begin{array}{l}\text { Placebo with BPH Meds } \\
(20.00 \%) \text { versus Placebo } \\
\text { FT CO }(1.56 \%)\end{array}$ & $<0.0001$ \\
\hline Surgery or AUR < 2 year & & $\begin{array}{c}\text { All BPH Meds }(15.58 \%) \\
\text { versus FT CO }(2.11 \%)\end{array}$ & $<0.0001$ & Surgery or AUR $<2$ year & & $\begin{array}{c}\text { Placebo not in CO }(10.64 \%) \\
\text { versus FT CO }(2.11 \%)\end{array}$ & $<0.0001$ \\
\hline $\begin{array}{l}\text { IPSS Last Capture } \\
\text { Responder }\end{array}$ & & $\begin{array}{l}\text { Placebo not in CO (48.68\%) } \\
\text { versus FT CO at last visit } \\
(80.70 \%)\end{array}$ & $<0.0001$ & $\begin{array}{l}\text { IPSS Last Capture } \\
\text { Responder }\end{array}$ & & $\begin{array}{l}\text { Placebo not in CO }(48.68 \%) \\
\text { versus Placebo FT CO at } \\
\text { last visit }(80.15 \%)\end{array}$ & $<0.0001$ \\
\hline $\begin{array}{l}\text { IPSS Last Capture } \\
\text { Responder }\end{array}$ & & $\begin{array}{l}\text { Placebo not in CO (48.68\%) } \\
\text { versus Last Data cap- } \\
\text { ture from 0020/0022, } \\
\text { FU042015, FU022016 } \\
(64.36 \%)\end{array}$ & 0.0008 & $\begin{array}{l}\text { IPSS Last Capture } \\
\text { Responder }\end{array}$ & & $\begin{array}{l}\text { Placebo not in CO }(48.68 \%) \\
\text { versus Placebo FT CO, } \\
\text { FU042015, FU022016 } \\
(67.52 \%)\end{array}$ & 0.0013 \\
\hline Surgery $<3$ year & & $\begin{array}{c}\text { Placebo not in CO }(16.44 \%) \\
\text { versus FT CO }(5.22 \%)\end{array}$ & 0.0048 & Surgery $<2$ year & & $\begin{array}{l}\text { Placebo not in CO }(9.04 \%) \\
\text { versus Placebo FT CO } \\
(0.78 \%)\end{array}$ & 0.0019 \\
\hline Surgery or AUR < 3 year & & $\begin{array}{c}\text { Placebo not in CO }(18.37 \%) \\
\text { versus FT CO }(6.09 \%)\end{array}$ & 0.0033 & Surgery or AUR $<2$ year & & $\begin{array}{l}\text { Placebo not in CO (10.64\%) } \\
\text { versus Placebo FT CO } \\
(1.56 \%)\end{array}$ & 0.0019 \\
\hline $\begin{array}{l}\text { Nocturia change from base } \\
\text { line }>0\end{array}$ & & $\begin{array}{l}\text { Placebo not in CO }(22.16 \%) \\
\text { versus FT CO at last visit } \\
(12.03 \%)\end{array}$ & 0.0024 & $\begin{array}{l}\text { Nocturia change from base } \\
\text { line }>0\end{array}$ & & $\begin{array}{l}\text { Placebo not in CO }(22.16 \%) \\
\text { versus FT CO at last visit } \\
(12.37 \%)\end{array}$ & 0.0117 \\
\hline Group & $N$ & $\begin{array}{l}\text { IPSS Change from } \\
\text { Baseline } \\
\text { Mean (SD) median }\end{array}$ & $\begin{array}{l}p \text { value } \\
\text { versus } \\
\text { Group } 1\end{array}$ & Group & $N$ & $\begin{array}{l}\text { IPSS Change from } \\
\text { Baseline } \\
\text { Mean (SD) median }\end{array}$ & $\begin{array}{l}p \text { value } \\
\text { versus } \\
\text { Group } 6\end{array}$ \\
\hline $\begin{array}{l}\text { Group 1: Placebo } \\
\text { patients not in CO }\end{array}$ & 189 & -4.08 (7.73) 0.00 & & $\begin{array}{l}\text { Group 6: Placebo } \\
\text { patients not in CO with } \\
\text { use of BPH medica- } \\
\text { tions }\end{array}$ & 62 & $-2.79(5.92)-1.00$ & \\
\hline $\begin{array}{l}\text { Group 2: All FT CO at } \\
\text { last visit }\end{array}$ & 316 & $-8.02(7.67)-8.00$ & $<0.0001$ & $\begin{array}{l}\text { Group 7: All CO } \\
\text { patients at last visit }\end{array}$ & 316 & $-8.02(7.67)-8.00$ & $<0.0001$ \\
\hline $\begin{array}{l}\text { Group 3: Placebo FT CO } \\
\text { at last visit }\end{array}$ & 131 & $-7.60(7.41)-6.00$ & $<0.0001$ & $\begin{array}{l}\text { Group 8: Placebo } \\
\text { patients in } \mathrm{CO} \text { at last } \\
\text { visit }\end{array}$ & 131 & $-7.60(7.41)-6.00$ & $<0.0001$ \\
\hline $\begin{array}{l}\text { Group 4: All FT CO } \\
\text { patients last data } \\
\text { capture }\end{array}$ & 275 & $-6.49(8.15)-5.00$ & 0.0011 & $\begin{array}{l}\text { Group 9: All CO } \\
\text { patients last visit } \\
\text { capture }\end{array}$ & 275 & $-6.49(8.15)-5.00$ & 0.0034 \\
\hline $\begin{array}{l}\text { Group 5: Placebo CO } \\
\text { patients last data } \\
\text { capture }\end{array}$ & 117 & $-6.50(7.90)-6.00$ & 0.0056 & $\begin{array}{l}\text { Group 10: Placebo } \\
\text { CO patients last data } \\
\text { capture }\end{array}$ & 117 & $-6.50(7.90)-6.00$ & 0.0058 \\
\hline
\end{tabular}

All other endpoints in Table 3 are secondary endpoints

FU follow-up, $C O$ crossover BPH medications: conventional oral BPH medications 0017/0018: NX02-0017 and NX02-0018 studies

${ }^{\mathrm{a}, \mathrm{b}}$ Co-Primary Endpoints 1 and 2 
Endpoint \#2) (Table 3); 9. LF superior FT responder results at all four IPSS improvement cut-offs -1 to -4 vs placebo $(p<0.0001)$. Although these studies were designed primarily as placebo controlled prospective randomized double blind parallel group trials and not as head-to-head comparator studies versus oral BPH treatments, there was extensive LT protocol follow-up which included in part comparator analysis of FT versus standard oral therapies in relation to outcomes of long-term IPSS change, incidence of BPH surgery, and AUR.

On the basis of 351 patients from studies 0017/0018, with patient individual discretion to return for elective re-injection of FT in studies 0020/0022, the administration of FT during a routine TRUS was considered well tolerated. Earlier trials $[17,18]$ feedback and questionnaires (NX02-0016, clinicaltrials.gov NCT00759135) had indicated the injection was not considered painful by patients (unpublished data).

Safety findings thus far indicate no known molecular side effects from FT. AE data and laboratory results were similar in FT and placebo groups. The only reported related AEs in both drug and placebo groups were from prophylactic antibiotic treatments and from the transrectal needle insertion; in both of these categories the events reported were mainly mild, transient and of infrequent requirement of additional treatment. There were no cases of urosepsis in FT-treated patients, and the rate of UTI was not increased compared to placebo. There were no significant sexual side effects reported, and semen analysis showed no significant changes from baseline. Anti-FT antibodies were undetectable. PK analysis showed no extraprostatic signal at any time point post-injection, indicating that FT has no measurable contact with tissues outside prostate.

These studies demonstrate statistically significant objective and subjective efficacy data. The PO variable (IPSS), responder rates, sexual function, and the prospective IPSS subgroups data are more subjective, while other efficacy variables (incidence outcomes of surgical treatment for BPH, AUR, prostate cancer) are objective. LF IPSS improvement was statistically significant in all studies, IPSS LF responder rates were statistically significant for all improvement cut-offs, and sexual function LF in placebo patients was mean worsening $(-0.88)$ compared to mean improvement in $\mathrm{FT}$ treated first line prior $\mathrm{BPH}$ treatment naïve patients $(+0.64, p=0.004)$. Several important FT pre-specified IPSS sub-groups showed significant LF results superior to placebo, including treatment naïve first-line patients (median -6.2 vs placebo -3.0 , $p<0.0001$ ). Pre-specified objective outcome analyses yielded consistently positive results in terms of reduced LF incidence of BPH surgery, reduced incidence of spontaneous AUR, and reduction in prostate cancer diagnosis. The LF FT re-injection studies also demonstrated statistically significant improvements compared to placebo groups in all of multiple endpoints of IPSS; in responder analysis; and in nocturia frequency improvement. Both the 2 pre-specified Primary Endpoints and all the 28 prespecified Secondary Endpoints in the LF CO analysis were statistically significant, showing clearly better outcomes after 24 and 36 months for all patient groups who received an injection of FT in Studies 0020/0022, as compared to groups of all non-CO placebo, or as compared to placebo who crossed over to conventional oral medications.

The published literature indicates that 1-year outcomes in BPH studies are less valid than previously assumed, insofar as strong placebo responses and effects are constantly encountered up to 1 year and perhaps longer [19-22]. The literature further indicates that long-term $(>1$ year) data capture and analyses are required to validate BPH treatments, given also that BPH is a condition that requires chronic treatment [19]. The results reported here are consistent with this well-described effect. Although there were statistical differences from baseline in FT-treated patients in all endpoints, there were no statistical differences from placebo at 1 year. The reasons for the first year strong placebo effect have been postulated to include regression to the mean and other hypotheses (patient and physician expectations, activation of reward circuitry, release of endogenous opioids, dopamine and other transmitters, psychological conditioning) [19-22]. In the studies reported herein, placebo Qmax improvement from baseline was $1.9 \mathrm{~mL} / \mathrm{s}$ which is similar in range to oral BPH medications, and if Qmax is considered a non-subjective outcome, it further suggests that placebo is probably at least partially active. Placebo injections into the prostate have been considered to be active controls in the reported literature due to a "mass effect" or to a change in prostate parenchyma or capsule, which may also in part explain the pronounced effect up to 1 year in all published trials of this nature [22].

Reduction in $\mathrm{PCa}$ incidence rate in FT-treated $\mathrm{BPH}$ patients was statistically significant. Patients in CO FT 0020/0022 had incidence after 4 years of $1.1 \%$ compared to non-CO placebo incidence of 5.3\% $(p=0.0116)$. FT 2.5 and $15 \mathrm{mg}$ single targeted injections to biopsy proven prostate cancer foci have been found to reduce clinical and biopsy progression and treatment outcome parameters in T1c prostate cancer patients in a multi-year study of 146 patients plus crossovers (Nymox, clinicaltrial.gov NCT \# NCT01620515, data on file). Although the present BPH studies used TRUS targeted to the transition zone, it is possible that the $10 \mathrm{~mL}$ injections also entered to some extent the peripheral prostate zones where PCa is usually found. Significant PCa reduction in the BPH studies reported here suggests that FT may have an inhibitory effect on clinically undetected low-grade PCa microfoci and/or precursor cells and lesions in quadrant locations where the FT BPH injections were bioavailable, 
but further study will be required to clarify the mechanism(s) of action and corroborate this finding.

Although these FT studies are the largest and longest duration clinical trials to have been completed for an intraprostatic injectable for $\mathrm{BPH}$, there are limitations to the number of adequately powered prospective subgroups that are possible. The efficacy and safety of FT combination treatments, of FT used in different patient study populations, the variability of dosing schedule remain to be answered by additional investigations. The inclusion criteria precluded enrollment of patients with more severe advanced BPH. It will be important, for example, to test FT in subjects who are in chronic retention due to BPH. Patients who have intractable severe LUTS but are poor surgical candidates are another important group where investigation may be warranted. Further studies will be needed to determine the impact of FT in relation to the gold standard TURP.

In conclusion, data from these 4 U.S. studies show statistically significant long-term improvement in BPH symptoms and objective outcomes including significant reduction in spontaneous AUR as well as the addition of BPH surgery; thus far (after a total of $>1700$ patient treatments including FT and placebo in U.S. trials to date since 2002) FT is well tolerated with an excellent safety profile. Hence, FT is a safe and efficacious clinic-based treatment for BPH involving an intraprostatic injection that requires only a few minutes to administer, with no catheter nor anesthesia requirements. FT injectable represents a novel, first in class BPH treatment modality.

Author contributions NS and RT: Project development, Data collection, manuscript writing and editing. ME, MB, BW, SK, SF, JB, RL, SR, JK, JS, BS, KG, AH, SG, and IG: Data collection, manuscript editing.

Funding Funded by Nymox Pharmaceutical Corporation.

\section{Compliance with ethical standards}

Conflict of interest Authors Gange, Shore, Richardson, Kaminetsky and Tutrone are consultants/speakers for NeoTract. Authors Gange, Shore, Kaminetsky, Levin are consultants for NxThera. Author Kaminetsky is a consultant for Meditech. Author Shore, Tutrone, Bidair are consultants/speakers for Nymox. Authors Tutrone, Hay own stock in Nymox.

Statement of human rights All procedures performed in studies involving human participants were in accordance with the ethical standards of the institutional and/or national research committee and with the 1964 Helsinki declaration and its later amendments or comparable ethical standards.

Open Access This article is distributed under the terms of the Creative Commons Attribution 4.0 International License (http://creativeco mmons.org/licenses/by/4.0/), which permits unrestricted use, distribution, and reproduction in any medium, provided you give appropriate credit to the original author(s) and the source, provide a link to the Creative Commons license, and indicate if changes were made.

\section{References}

1. Gravas S, Bach T, Bachmann A, Drake M et al (2015) Guidelines on the management of non-neurogenic male lower urinary tract symptoms (LUTS), incl benign prostatic obstruction (BPO). Eur Assoc Urol

2. Oelke M, Bachmann A, Descazeaud A et al (2013) EAU Guidelines on the treatment and follow-up of non-neurogenic male lower urinary tract symptoms including benign prostatic obstruction. Eur Urol 64:118-140

3. McVary KT, Roehrborn CG, Avins AL et al (2011) Update on AUA guideline on the management of benign prostatic hyperplasia. J Urol 185:1793-1803

4. NICE National Clinical Guideline Centre for Acute and Chronic Conditions. Lower urinary tract symptoms (2010) The management of lower urinary tract symptoms in men. Clinical Guideline No 9.-London (UK) 34

5. Speakman M, Kirby R, Doyle S, Ioannou C (2015) Burden of male lower urinary tract symptoms (LUTS) suggestive of benign prostatic hyperplasia (BPH) - focus on the UK. BJU Int 115:508-519

6. Abrams P, Chapple C, Khoury S, Roehrborn C, de la Rosette J (2013) Evaluation and treatment of lower urinary tract symptoms in older men. J Urol 189:S93-S101

7. Lukacs B, Cornu JN, Aout M et al (2013) Management of lower urinary tract symptoms related to benign prostatic hyperplasia in real-life practice in France: a comprehensive population study. Eur Urol 64:493-501

8. Madersbacher S, Marszalek M, Lackner J, Berger P, Schatzl G (2007) The long-term outcome of medical therapy for BPH. Eur Urol 51:1522-1533

9. Souverein PC, van Riemsdijk MM, de la Rosette J, Opdam PC, Leufkens HGM (2005) Treatment of benign prostatic hyperplasia and occurrence of prostatic surgery and acute urinary retention: a population-based cohort study in the Netherlands. Eur Urol 47:505-510

10. Cindolo L, Pirozzi L, Fanizza C, Romero M et al (2015) Drug adherence and clinical outcomes for patients under pharmacological therapy for lower urinary tract symptoms related to benign prostatic hyperplasia: population-based cohort study. Eur Urol 68:418-425

11. Roehrborn CG, Barkin J, Siami P et al (2011) Clinical outcomes after combined therapy with dutasteride plus tamsulosin or either monotherapy in men with benign prostatic hyperplasia (BPH) by baseline characteristics: 4-year results from the randomized, double-blind combination of Avodart and Tamsulosin (CombAT) trial. BJU Int 107:946-954

12. Theoret MR, Ning YM, Zhang JJ, Justice R, Keegan P, Pazdur $\mathrm{R}$ (2011) The risks and benefits of $5 \alpha$-reductase inhibitors for prostate-cancer prevention. N Engl J Med 365:97-99

13. Nichol MB, Knight TK, Wu J, Barron R, Penson. DF (2009) Evaluating use patterns of and adherence to medications for benign prostatic hyperplasia. J Urol 181:2214-2222

14. Cindolo L, Pirozzi L, Sountoulides P et al (2015) Patient's adherence on pharmacological therapy for benign prostatic hyperplasia (BPH)-associated lower urinary tract symptoms (LUTS) is different: is combination therapy better than monotherapy? BMC Urol 15:96 
15. Fwu CW, Eggers P, Kirkali Z, McVary KT, Burrows PK, Kusek JW (2014) Change in sexual function in men with lower urinary tract symptoms/benign prostatic hyperplasia associated with long-term treatment with doxazosin, finasteride and combined therapy. J Urol 191:1828-1834

16. Zong HT, Peng XX, Yang CC, Zhang Y (2012) The impact of transurethral procedures for benign prostate hyperplasia on male sexual function: a meta-analysis. J Androl 33:427-434

17. Shore N, Cowan B (2011) The potential for NX-1207 in benign prostatic hyperplasia: an update for clinicians. Ther Adv Chronic Dis 2:377-383

18. Shore N (2010) NX-1207: a novel investigational drug for the treatment of benign prostatic hyperplasia. Expert Opin Investig Drugs 19:305-310

19. Eredics K, Madersbacher S, Schauer I (2017) A relevant mid-term (12 months) placebo effect on lower urinary tract symptoms and maximum flow rate in male LUTS/BPH-a meta-analysis. https ://doi.org/10.1016/j.urology.2017.05.011

20. Fässler M, Meissner K, Kleijnen J, Hróbjartsson A, Linde K (2015) A systemic review found no consistent difference in effect between more and less intensive placebo interventions. J Clin Epidemiol 68:442-451

21. van Leeuwen J, Castro R, Busse M, Bemelmans B (2006) The placebo effect in the pharmacologic treatment of patients with lower urinary tract symptoms. Eur Urol 50:440-453

22. Welliver C, Kottwitz M, Feustel P, McVary K (2015) Clinically and statistically significant changes seen in sham surgery arms of randomized, controlled benign prostatic hyperplasia surgery trials. J Urol 194:1682-1687

\title{
Affiliations
}

\author{
Neal Shore ${ }^{1}\left[\right.$. Ronald Tutrone ${ }^{2} \cdot$ Mitchell Efros $^{3} \cdot$ Mohamed Bidair $^{4} \cdot$ Barton Wachs $^{5} \cdot$ Susan Kalota ${ }^{6}$. \\ Sheldon Freedman ${ }^{7}$. James Bailen ${ }^{8} \cdot$ Richard Levin $^{9} \cdot$ Stephen Richardson $^{10}$. Jed Kaminetsky ${ }^{11}$. Jeffrey Snyder ${ }^{12}$. \\ Barry Shepard ${ }^{13} \cdot$ Kenneth Goldberg $^{14} \cdot$ Alan Hay $^{15}$. Steven Gange ${ }^{16} \cdot$ Ivan Grunberger $^{17}$ \\ Carolina Urologic Research Center, Myrtle Beach, SC, USA \\ 2 Chesapeake Urology Research Associates, Baltimore, MD, \\ USA \\ 3 Accumed Research, Garden City, NY, USA \\ 4 San Diego Clinical Trials, San Diego, CA, USA \\ 5 Atlantic Urology Medical Group, Long Beach, CA, USA \\ 6 Urological Associates of Southern Arizona, Tucson, AZ, \\ USA \\ 7 Freedman Urology, Las Vegas, NV, USA \\ 10 Jean Brown Research, Salt Lake City, UT, USA \\ 11 University Urology, New York, NY, USA \\ 12 Genitourinary Surgical Consultants, Denver, CO, USA \\ 13 Urological Surgeons of Long Island, Garden City, NY, USA \\ 14 U T Southwestern Dept of Urology, Lewisville, TX, USA \\ 15 Willamette Urology, Salem, OR, USA \\ 16 Summit Urology Group, Salt Lake City, UT, USA \\ 17 Brooklyn Urology, Brooklyn, NY, USA
}

8 First Urology, Louisville, KY, USA

9 Chesapeake Urology Research Associates, Towson, MD, USA 